\title{
An Assessment of the Market Risk Solvency Capital Requirement Simplifications for Insurance Undertakings
}

\author{
Thomas Poufinas ${ }^{*}$, Panagiota Tsitsika² \\ ${ }^{1}$ Department of Economics, Democritus University of Thrace, Thrace, Greece \\ ${ }^{2}$ Graduate Program in Business Mathematics, University of Athens \& Athens University of Economics and Business, Athens, \\ Greece \\ Email: *tpoufinas@gmail.com
}

How to cite this paper: Poufinas, T. and Tsitsika, P. (2018) An Assessment of the Market Risk Solvency Capital Requirement Simplifications for Insurance Undertakings. Theoretical Economics Letters, 8, 2363-2387. https://doi.org/10.4236/tel.2018.811153

Received: May 14, 2018

Accepted: August 12, 2018

Published: August 15, 2018

Copyright (C) 2018 by authors and Scientific Research Publishing Inc. This work is licensed under the Creative Commons Attribution International License (CC BY 4.0).

http://creativecommons.org/licenses/by/4.0/ Open Access

\begin{abstract}
The Solvency II regulatory framework has been implemented as of January 1st, 2016 and among other things it introduced economic risk-based capital requirements across all EU Member States for the first time, applicable for insurance and reinsurance undertakings. Similar to Basel II whose scope is banks, the Solvency II directive provides a new regime based on three pillars for insurers and reinsurers: 1) pillar 1: harmonized valuation and risk based capital requirements, 2) pillar 2: harmonized governance and risk management requirements and 3) pillar 3: harmonized supervisory reporting and public disclosure. The Solvency Capital Requirement (SCR) should correspond to the Value-at-Risk of the basic own funds of an insurance or reinsurance undertaking subject to a confidence level of $99.5 \%$ over a one-year period. The Solvency II directive provides a range of methods to calculate the SCR. This allows insurance or reinsurance undertakings to choose a method that is proportionate to the nature, scale and complexity of the risk that is measured. In order to calculate the SCR, an insurance undertaking can use a fully internal model, the standard formula and a partial internal model, the standard formula with undertaking-specific parameters, the standard formula as it is or a simplification. When introducing a simplification, the SCR estimate could deviate from the calculation without the simplification. A simplification could lead in important/crucial information missing from the SCR calculation. In some occasions the SCR is overestimated and in some others it is underestimated. It is therefore of interest to find the range of this deviation, potential bounds-if any and the effect it can have on the required capital. In this paper we attempt to measure this deviation for simplifications pertaining to the interest rate risk for insurance companies.
\end{abstract}




\section{Keywords}

Solvency II, Solvency Capital Requirement, Simplification, Market Risk, Interest Rate, Duration

\section{Introduction}

As history has proved every entity is vulnerable when it comes to terms of risk and as such it is asked to address it via a risk management process and/or framework. Such a process (or framework) includes the identification of the risk, the measuring of the risk and finally the management of the risk. The management of the risk incorporates several alternatives such as retaining the risk, hedging part or all of the risk, reducing (mitigating) the risk or totally dropping the risk. Identifying the source of the risk is one step of the process; predicting the potential risk and quantifying it, are another. Whatever are the means an entity has for managing potential risks, one thing is for sure: it should be prepared in terms of capital to face the potential loss of a risk arising or more accurately of the biggest risk arising. The question is how to remain solvent when a risk occurs?

Within the European Union each country had its own set of laws in terms of solvency capital requirements for insurance (or reinsurance) companies, thus exhibiting a fragmented environment. To answer the aforementioned question as well as to address the differences in the legal frameworks of the various countries, the European Union Regulatory Authorities implemented a uniform regulatory framework, the Solvency II Regulatory Framework, so as to ensure adequate policyholder protection [1]. As a matter of fact it protects all stakeholders, namely the policyholders, the shareholders, the creditors and the regulators, as it provides a common playing field for insurers (or reinsurers). The aim was to eliminate the most serious differences between the laws of the European Union (EU) Member States with regards to the rules to which insurance and reinsurance undertakings are subject. Such a common regulatory/legal framework would facilitate the insurance and reinsurance activity through the internal EU market [1].

The insurance and reinsurance undertakings should meet specific Solvency Capital Requirements, so as to remain solvent. This means that they need to maintain the necessary capital so as to cover for the risks they are exposed to. "Solvency II introduces economic risk-based capital requirements across all EU Member States for the first time. These new capital requirements will be more risk-sensitive and more sophisticated than in the past, thus enabling a better coverage of the real risks run by any particular insurer. The new requirements move away from a crude 'one-model-fits-all' way of estimating capital requirements to requirements that better fit insurers' risk profiles. Solvency II also puts a greater focus on risk management, as well as introducing stricter rules on the 
disclosure of certain information publicly" [2].

Consequently, the economic capital that an insurance company sets aside must cover all types of risk, such as market, credit, insurance and operational. This capital must be sufficient to cover for losses that occur at a $99.5 \%$ confidence level or equivalently at a $99.5 \%$ Value-at-Risk (VaR) level, over a one-year horizon. This is applicable under all methodologies applied, i.e. the standard formula, a simplification of the standard formula, an internal model and a partial internal model. Market risk is one of the types of risk that can be relatively easily quantified with the aforementioned metric. The economic capital required to cover for such risk can be also calculated in a relatively straightforward manner compared with other types of risk. One source of market risk is interest rate. The risk in this case is the shift of the risk-free rate and/or of the spread. The most well known measure of this risk is the duration. The duration is used to calculate the VaR of fixed income asset and liabilities.

However, not all insurance companies are the same, therefore, the Solvency II Directive provisions for proportionality. The rationale of the regulator is stated in the directive: "In order to ensure the effectiveness of the supervision all actions taken by the supervisory authorities should be proportionate to the nature, scale and complexity of the risks inherent in the business of an insurance or reinsurance undertaking, regardless of the importance of the undertaking concerned for the overall financial stability of the market" [1]. This implies that the "Regulation provides for numerous simplifications in quantitative requirements, where justified by the nature, scale and complexity of the risks that the (insurance or reinsurance undertakings) face" [2]. One such simplification is of the calculation of the capital requirement for interest rate risk (Article 103, European Commission [2]), well intended for captive insurance or reinsurance undertakings. In this paper we evaluate the accuracy of the simplified calculations against the standard formula calculations and measure the distance between the two calculations. As a matter of fact we realize that this distance in not bounded (theoretically) and we demonstrate that via numerical applications. In order to calculate the interest rate capital requirement and the deviation between the two methods we employ the value of the assets and the liabilities and the time to maturity or the duration, as indicated by the relevant formulas.

\subsection{The History of Solvency II}

It is worth devoting a short paragraph to the history of the Solvency II requirements for the non-expert readers. Solvency II practically pertains to solvency margin requirements in Europe, whose origin goes back to 1973 with the non-life directive, continues with the life directive in 1979 and extends with the third life and non-life directives in 1992. In 2002 the Solvency I framework is launched to incorporate all previous directives and in 2009 the Solvency II framework commences [3] to be implemented though in 2016 for member states of the European Union. The main steps in reaching the Solvency II framework 
commenced in 2004, when the European Commission issued three waves of calls for advice to the Committee of European Insurance and Occupational Pensions Supervisors (CEIOPS). In 2007 the European Commission adopted the Solvency II proposal, which was followed by an amended proposal in 2008. A series of five Quantitative Impact Studies (QIS) studies took place from 2005 to 2010 in order to assess the capital requirements of the insurance industry in the intended Solvency II framework.

Solvency II was deemed necessary as over its 40 years of existence, the Solvency I regime showed structural weaknesses. It was not risk sensitive and a number of key risks, including market, credit and operational risks were either not captured at all in capital requirements or were not properly taken into account in the one-model-fits-all approach. This lack of risk sensitivity had the following consequences: 1) owing to its simplistic model, the Solvency I framework does not lead to an accurate assessment of each insurer's risks; 2) it does not ensure accurate and timely intervention by supervisors; 3 ) it does not entail an optimal allocation of capital, i.e. an allocation which is efficient in terms of risk and return for shareholders [4].

The Solvency II framework, like the Basel framework for banks, proposes to remedy these shortcomings. It is divided into three "pillars": 1) pillar 1, which sets out quantitative requirements, including the rules to value assets and liabilities, to calculate capital requirements and to identify eligible own funds to cover those requirements; 2) pillar 2, which sets out requirements for risk management, governance, as well as the details of the supervisory process with competent authorities, so as to ensure that the regulatory framework is combined with each undertaking's own risk-management system and informs business decisions; 3) pillar 3, which addresses transparency, reporting to supervisory authorities and disclosure to the public, thereby enhancing market discipline and increasing comparability, leading to more competition. Capital requirements under Solvency II are forward-looking and economic, i.e. they are tailored to the specific risks borne by each insurer, allowing an optimal allocation of capital across the EU [4].

Of interest to the problem we tackle in this paper is that the capital requirements are defined along a two-step ladder, including the solvency capital requirements (SCR) and the minimum capital requirements (MCR), in order to trigger proportionate and timely supervisory intervention. The new regime eliminates the restrictions that were imposed by Member States on the composition of insurers' investment portfolios. Instead, insurers are free to invest according to the "prudent person principle" and capital requirements will depend on the actual risk of investments.

\subsection{Literature Review}

The key concept of the interest rate risk capital requirement is that of duration. Although known, we look briefly at the historical background to understand its 
importance in the Solvency II framework. Back in 1970 the interest rates were low, the coupon flows were in comparison to the principal payment very small and the maturity dates were very similar. Thus maturity was a good measure to interpret the bond's life [5]. As the environment became more turbulent the need for another measure became apparent. The measure of duration served that need [6]. It is now commonly known as the Macaulay Duration had already been introduced in 1938 by Frederic Macaulay but it wasn't until later that it gained recognition. Thus in 1952 Frank Redington [7] published his work on immunization using the Macaulay Duration. The theory of Redington would later develop in the immunization portfolio strategy. Later on in 1969 Fisher and Weil [8] also studied interest rate fluctuations. In 1986 the First International Conference in Insurance Solvency took place in Philadelphia [9]. Finally in 1994 JPMorgan introduced Risk Metrics and popularized Value-at-Risk [10].

When it comes to market risk and in particular interest rate risk, there is a rich literature with regards to the economic capital calculation. One can see for example, Marrison [11]. Van Beers and Elshof [12] study the simplifications assumed in the standard formula with regards to interest rate risk for the evaluation of the SCR. Their interest is in whether the Solvency II standard formula provides a good measure for the interest rate risk an insurer is facing. They conclude that the standard formula incorporates simplifications that can lead to serious drawbacks in the management of interest rate risk, especially with liabilities with high expected premium income, long term guarantees and/or a material risk margin. They recommend an alternative method.

Interest rate risk is considered not adequately captured in the current low interest rate environment and alternatives are assessed. EIOPA (European Insurance and Occupational Pensions Authority) has included the topic in its discussion/consultation paper launched in December 2016 [12]. The purpose of the paper is to give to the insurance sector the opportunity to react or identify points of improvement in the Solvency II framework. The issue that emerged with regards to the interest rate risk is that the relative stress factor approach does not seem to be appropriate when interest rates are negative.

Gatzert and Martin [13] provide an alternative approach to the standard model, via a partial internal risk model using a model that accounts for credit, equity, and interest rate risk inherent in a portfolio of stocks and bonds. They find that the SCR strongly depend on the quality and composition of an insurer's asset portfolio and that model risk in regard to model choice and calibration plays an important role in the quantification.

Horing [14] studies whether the new regulatory capital requirements for market risk are a binding constraint for European insurers by comparing the required market risk capital of the Solvency II standard model with the Standard \& Poor's rating model. His results show that Solvency II does not seem to be a binding capital constraint for market risk and thus would not significantly influence the insurance companies' investment strategies. 
Braun et al. [15] optimize a life insurance company's asset allocation in the context of classical portfolio theory when the firm has to follow the market risk capital (including interest rate risk) requirements of Solvency II. Their results indicate that the standard formula suffers from severe shortcomings that can affect asset management decisions. Consequently, there can be adverse impact on certain parts of the European insurance sector.

Peleckiene and Peleckis [16] investigate the results of the last impact assessment with long-term guarantees to the current Solvency II framework to cope with artificial volatility and low interest rate environment and to ensure both transparency and level-playing field. After the impact assessment EIOPA analyzed each measure against the objectives and recommended the inclusion of measures such as extrapolation, classical matching adjustment, transitional measures, and extension of the recovery period, not to include the so-called extended matching adjustment on the basis that it would not provide sufficient policyholder protection.

We realize that the simplifications as introduced [2] for insurance companies, have not been the objective of research so far. This is where our research focuses and there lies the novelty of our contribution.

\section{Background Discussion}

Market risk, as borne by insurance companies, is measured via the market risk module (of the standard formula or other approach). It calculates the SCR that is needed in order to cover for the market risk. Similar modules are used for all types of risks. Market risk is created from the volatility of market prices of financial instruments. We treat the assets and the liabilities of an insurance company as financial instruments. The influence of the volatility of financial variables such as stock prices, interest rates, real estate prices and foreign exchange rates reflects the exposure to market risk and as such qualifies them as potential sources of market risk. For this reason the market risk module for insurance companies consists of the following sub-modules: 1) interest rate risk sub-module; 2) equity risk sub-module; 3) property risk sub-module; 4) spread risk sub-module; 5) currency risk sub-module and 6) market risk concentrations sub-module.

The capital requirement for market risk according to Article 164 of the Delegated Regulation (EU) 2015/35 [2] is calculated by the following equation:

$$
S C R_{\text {market }}=\sqrt{\operatorname{Corr}_{i, j} \cdot S C R_{i} \cdot S C R_{j}}
$$

where

1) $i, j$ are market risk sub-modules and the sum takes into account all the combinations $i, j$ of sub-modules of the market risk module.

2) Corr $_{i, j}$ is the correlation parameter for market risk between sub-modules $i, j$ (Table 1).

3) $S C R_{i}$ and $S C R_{j}$ are the capital requirement for sub-modules $i, j$ respectively. 
Table 1. Correlation matrix.

\begin{tabular}{ccccccc}
\hline I & Interest rate & Equity & Property & Spread & Concentration & Currency \\
\hline Interest rate & 1 & $\mathrm{~A}$ & $\mathrm{~A}$ & $\mathrm{~A}$ & 0 & 0.25 \\
Equity & $\mathrm{A}$ & 1 & 0.75 & 0.75 & 0 & 0.25 \\
Property & $\mathrm{A}$ & 0.75 & 1 & 0.5 & 0 & 0.25 \\
Spread & $\mathrm{A}$ & 0.75 & 0.5 & 1 & 0 & 0.25 \\
Concentration & 0 & 0 & 0 & 0 & 1 & 0 \\
Currency & 0.25 & 0.25 & 0.25 & 0.25 & 0 & 1 \\
\hline
\end{tabular}

In accordance with Article 165 of the Delegated Regulation (EU) 2015/35 [2] when the capital requirement for interest rate risk is the sum, over all currencies, of the capital requirements for the risk of an increase in the level (term structure) of interest rates, then the parameter $\mathrm{A}$ is equal to zero. In all other cases the parameter A equals to 0.5 .

\subsection{Interest Rate Risk Sub-Module}

When the absolute level of interest rates changes or the spread between two rates widens or narrows then an investor faces interest rate risk. In general any difference in the shape of the yield curve is related to interest rate risk. Due to the fact that the value of assets and liabilities of an insurance company strongly depends on the level of interest rates, it is essential that a different sub-module gives the capital requirement for interest rate risk.

The capital requirement for an insurance company for interest rate risk in accordance to Article 165 of the Delegated Regulation (EU) 2015/35 [2] is equal to the larger of the following:

1) The aggregate capital requirements for all currencies for the risk of an increase in the term structure of interest rates.

2) The aggregate capital requirements for all currencies for the risk of a decrease in the term structure of interest rates.

Because assets and liabilities are interest rate sensitive, any increase or decrease, as described above could influence the basic own funds. According to Table 2 if an instantaneous change in the level of interest rate happens, the capital requirement for the risk of that change is considered to be equal to the loss in the basic own funds that we would have if the same change in basic risk free interest rates occurred. The increase or decrease refers to funds of a certain currency at interest rates that correspond to different maturities.

The capital requirement for the interest rate risk is considered to be the result of two pre-defined scenarios [17] [18] [19]:

$$
\begin{gathered}
S C R_{\text {int }}^{U p}=\Delta N A V \mid U p \\
S C R_{\text {int }}^{\text {Down }}=\Delta N A V \mid \text { Down }
\end{gathered}
$$

where $\triangle N A V \mid U p$ and $\triangle N A V \mid$ Down represent the $\triangle N A V$ that is caused 
Table 2. Stress factors.

\begin{tabular}{|c|c|c|}
\hline Maturity (years) & Increase (\%) & Decrease (\%) \\
\hline 1 & 70 & 75 \\
\hline 2 & 70 & 65 \\
\hline 3 & 64 & 56 \\
\hline 4 & 59 & 50 \\
\hline 5 & 55 & 46 \\
\hline 6 & 52 & 42 \\
\hline 7 & 49 & 39 \\
\hline 8 & 47 & 36 \\
\hline 9 & 44 & 33 \\
\hline 10 & 42 & 31 \\
\hline 11 & 39 & 30 \\
\hline 12 & 37 & 29 \\
\hline 13 & 35 & 28 \\
\hline 14 & 34 & 28 \\
\hline 15 & 33 & 27 \\
\hline 16 & 31 & 28 \\
\hline 17 & 30 & 28 \\
\hline 18 & 29 & 28 \\
\hline 19 & 27 & 29 \\
\hline 20 & 26 & 29 \\
\hline 90 & 20 & 20 \\
\hline
\end{tabular}

due to the revaluation of the interest rate dependent items when interest rates rise or fall respectively. $N A V$ is the Net Asset Value, whereas $\triangle N A V$ denotes the change in the Net Asset Value. The stress causing these changes is instantaneous.

The new term structures are the result of the multiplication of the current interest rate curve with the stress factors $\left(1+s_{U p}\right)$ and $\left(1+s_{\text {Down }}\right)$. These stress factors for the upward or the downward stress are found in Table 1 and correspond to different maturities. To understand how the above stress factors are used we consider three examples/cases:

1) When the maturity is lower than one year we use the stress factor that is given for the maturity of one year, meaning $70 \%$ or $75 \%$ for an increase or a decrease respectively.

2) When the maturity is longer than 90 years we use the given stress factor for a maturity of 90 years, meaning $20 \%$ in both cases.

3) For other maturities, e.g. 1.5 years, which fall between the given values we use linear interpolation to find the value of the stress factor.

The change of basic risk free rates at any maturity should be at least one per- 
centage point when there is an increase. However, where the unstressed rate is less than $1 \%$ the shocked rate should be nil. This constraint does not apply to index linked bonds (i.e. those which contain no material inflation risk).

As a result we receive four different capital requirements.

1) The first two are the aforementioned $S C R_{\text {int }}^{U p}$ and $S C R_{\text {int }}^{\text {Down }}$.

2) We also get capital requirements for an upward or downward shock in which the loss absorbing capacity is included. The notation for these capital requirements are $n S C R_{\text {int }}^{U p}$ and $n S C R_{\text {int }}^{\text {Down }}$ respectively.

We choose the highest capital requirement that includes the loss absorbing capacity for technical provisions.

The SCR could be also calculated by using a simplified method or simplification. In particular the insurance or reinsurance undertakings could use these methods in order to value assets and liabilities and generally calibrate technical provisions arising as a result of determining the impact of a scenario that we have earlier mentioned. This occurs under the condition that the simplification does not lead to a misstatement of SCR or if it does the calculated SCR is higher than the SCR of the standard formula.

\subsection{Simplifications}

With simplified method or simplification reference is made to a condition where in agreement with the proportionality principle a valuation technique has been simplified. As mentioned earlier insurance and reinsurance undertakings should use methods to calculate technical provisions which are proportionate to the nature, scale and complexity of the risks underlying their insurance and reinsurance obligations.

In order to define whether a method is proportionate, insurance and reinsurance undertakings must perform an assessment of the nature, scale and complexity of the risks underlying their obligations. They should also perform a quantitative or qualitative evaluation of the error introduced in the results of the method that is caused due to any variation in the assumptions underlying the method (in relation to the risks) or in the results of the assessment.

\subsubsection{Simplified Calculation of Interest Rate Sub-Module}

When using a simplified method to calculate the SCR for the market risk we use a simplified duration. There is a certain duration assigned to each maturity as shown in the following table.

We basically group the assets in buckets of maturity and cash flows onto a limited number of points on the yield curve. This enables us to reduce the data we would normally need to use and as a consequence to save valuable time. The capital requirements for an upward or downward shock in the term structure of interest rates $(I R)$ are the following:

$$
\begin{aligned}
I R_{u p}= & \sum_{i} M V A L_{i} \cdot \text { dur }_{i} \cdot \text { rate }_{i} \operatorname{stress}_{(i, u p)} \\
& -\sum_{l o b} B E_{l o b} \cdot d u r_{l o b} \cdot \text { rate }_{l o b} \cdot \operatorname{stress}_{(l o b, u p)}
\end{aligned}
$$




$$
\begin{aligned}
I R_{\text {down }}= & \sum_{i} M V A L_{i} \cdot \text { dur }_{i} \cdot \text { rate }_{i} \text { stress }_{(i, \text { down })} \\
& -\sum_{l o b} B E_{l o b} \cdot \text { dur }_{\text {lob }} \cdot \text { rate }_{\text {lob }} \cdot \text { stress }_{(\text {lob }, \text { down })}
\end{aligned}
$$

where

1) $M V A L_{i}$ is the market value of the difference between assets and liabilities for a specific maturity interval $i$.

2) $d u r_{i}$ denotes the simplified duration that is set for the maturity interval $i$.

3) rate $_{i}$ is the risk free rate for $d u r_{i}$ for a maturity interval $i$.

4) $\operatorname{stress}_{(i, u p)}$, stress $_{(i, \text { down })}$ are the stress factors from the given table for an upward stress and a downward stress of interest rate respectively.

5) $l o b$ denotes the lines of business.

6) $B E_{l o b}$ refers to the best estimation for lob.

7) $d u r_{l o b}$ is the modified duration of the $B E_{l o b}$.

8) rate $_{l o b}$ is the risk free rate for $d u r_{l o b}$.

9) $\operatorname{stress}_{(l o b, u p)}$, stress $_{(l o b, d o w n)}$ are the stress factors for an upward stress and a downward stress of interest rate respectively.

As before, we have two cases, one for the risk of an increase in interest rates and one for the risk of a decrease in interest rates. The maturity intervals $i$ are grouped as we mentioned above.

When using a simplified method for calculating $S C R_{i n t}$ it is important to assume that all assets and liabilities which are sensitive to changes in the level of interest rates are materially less diversified concerning maturity intervals and lines of business compared to those of the standard formula [20].

The calculation of SCR with a simplified method should be done separately for assets of different currency. The lines of business according Annex I of Directive 2009/138/EC are life insurance and reinsurance obligations, non-life insurance obligations, proportional non-life reinsurance obligations and non-proportional non-life reinsurance obligations.

\subsubsection{Duration Simplifications}

Duration is a measure of a portfolio's exposure to changes in the term structure of interest rates. It measures the sensitivity of the value of an item i.e. bond to changes in its yield. Therefore, if we know the duration and the possible shift in the term structure of interest rates, we have a measure of the possible loss an undertaking could face. The duration of a portfolio is the weighted average of the durations of the assets and liabilities of which the portfolio consists of. The weight of each asset or liability is equal to the value of the asset or the liability divided by the value of the portfolio.

When using a simplified method in order to calculate the solvency capital requirement, a simplified duration is used. All assets and liabilities are grouped in duration bands. The grouping is made only for assets or only for liabilities. The duration bands are those mentioned earlier in Table 3. There is a matching between the assets that correspond to certain duration and liabilities of similar duration. 
Table 3. Duration simplification.

\begin{tabular}{cc}
\hline Maturity of Assets & Duration \\
\hline$<1$ year & 0.5 year \\
$1-3$ years & 2 years \\
$3-5$ years & 4 years \\
$5-10$ years & 7 years \\
$>10$ years & 12 years \\
\hline
\end{tabular}

Considering the duration years in Table 3 we notice that there are durations close enough to the initial maturities but there are other durations that deviate significantly from the initial maturity. For example when the maturity of an asset is 20 years then the simplified duration for maturities longer than 10 years is used, which is equal to 12 years. Whether the maturity of an asset or a liability is 11 years or 20 years it does not make any difference in the value of the simplified duration used for the SCR calculation. This could possibly lead to a misstatement of capital requirement. In fact as we are going to prove later, this could lead to a smaller solvency capital requirement.

We consider a portfolio of assets and liabilities. Let as assume that the portfolio consists only of bonds with different durations. Then the duration of the portfolio will be given by the following equation:

$$
D_{\text {portf }}=\sum_{i=1}^{N} w_{i} D_{i},
$$

where $w_{i}$ is the weight of each bond so that their sum equals 1 . Each weight is equal to the value of the bond divided by the value of the portfolio. We assume now that in the calculation of the simplified duration of the portfolio, new weights are being used. The simplified duration of the portfolio is given by the following equation:

$$
D_{\text {portf }}^{\prime}=\sum_{i=1}^{N} w_{i}^{\prime} D_{i}^{\prime} .
$$

The sum of the new weights should sum as well to one. As described previously the duration mapping of the assets and the liabilities when using the simplified formula is expressed by:

$$
\begin{aligned}
D_{\text {portf }}^{\prime}= & w_{1}^{\prime} 0.5+w_{2}^{\prime} 2+\left(w_{3}^{\prime}+w_{4}^{\prime}\right) 4+\left(w_{5}^{\prime}+w_{6}^{\prime}+w_{7}^{\prime}+w_{8}^{\prime}+w_{9}^{\prime}\right) \\
& +\left(w_{10}^{\prime}+\sum_{i=11}^{N} w_{i}^{\prime} D_{i}^{\prime}\right) 12
\end{aligned}
$$

Another way to use the simplified formula and take a more accurate result would be to use the following formula that gives a better weighted average of each asset or liability in respect to its duration:

$$
\begin{aligned}
D_{\text {porff }}^{\prime \prime}= & \left(\frac{w_{1}^{\prime}}{2}\right) 0.5+\left(\frac{w_{1}^{\prime}}{2}+w_{2}^{\prime}+\frac{w^{\prime}}{2}\right) 2+\left(\frac{w^{\prime}}{2}+w_{4}^{\prime}+\frac{w_{5}^{\prime}}{2}\right) 4 \\
& +\left(\frac{w_{5}^{\prime}}{2}+w_{6}^{\prime}+w_{7}^{\prime}+w_{8}^{\prime}+w_{9}^{\prime}+\frac{w_{10}^{\prime}}{2}\right) 7+\left(\frac{w_{10}^{\prime}}{2}+\sum_{i=11}^{N} w_{i}^{\prime} D_{i}^{\prime}\right) 12
\end{aligned}
$$


A way to evaluate whether the use of the simplified formula leads to consistent results is to calculate the difference between the actual duration and the simplified duration of the portfolio:

$$
D_{\text {portf }}-D_{\text {portf }}^{\prime} \text { or } D_{\text {portf }}-D_{\text {portf }}^{\prime \prime}
$$

In the following sections we will investigate, both with the appropriate mathematics (algebraic calculations) and numerical applications the difference in the SCR without and with the simplifications as set out by the regulator, applying the aforementioned principle to the capital requirement calculations.

\section{The Impact of the Simplifications}

In this section we will try to assess the impact of the simplifications on the interest rate risk. To elaborate we start with a portfolio consisting of only one bond with maturity date equal to $N$ years, then we extend our arguments to a portfolio of bonds and finally we consider both assets and liabilities.

\subsection{Asset Only: Zero-Coupon Bond}

In the case of a zero coupon bond in the asset side only, with a price (or present value) of $P_{A}$ and duration $D_{A}$, if the interest rate $r$ shifts by $\Delta r$, then the change in the value of the portfolio $\Delta P_{A}$ is (approximately, denoted by $\approx$ ) equal to

$$
\Delta P_{A} \approx-\frac{1}{1+r} D_{A} P_{A} \Delta r
$$

if the actual duration $D_{A}$ is used or

$$
\Delta P_{A}^{S} \approx-\frac{1}{1+r} D_{A}^{S} P_{A} \Delta r
$$

if the simplified duration $D_{A}^{S}$ is used. This is the simplified duration closest to the actual one.

The error of the simplification is the difference between the changes in the value of the bond (which is in this case the asset portfolio) with the use of the actual and the simplified duration.

$$
\begin{gathered}
\text { Error }=\left(\Delta P_{A}-\Delta P_{A}^{S}\right)=-\frac{1}{1+r} P_{A} \Delta r\left(D_{A}-D_{A}^{S}\right), \\
\text { Error }=c(r)\left(D_{A}-D_{A}^{S}\right)=c(r)\left(T_{A}-T_{A}^{S}\right),
\end{gathered}
$$

where $T_{A}$ is the maturity of the zero-coupon bond, $T_{A}^{S}$ is the maturity with the simplification and $c(r)$ is a function of $r$. For a zero-coupon bond with a maturity $T_{A}=N=D_{A}$ longer than 12 years $(N>12)$ we see that

$$
\text { Error }=c(r)(N-12) \text {. }
$$

Thus the error is a function of $r$ multiplied with the term $(N-12)$. It is important to remember that 12 years is the maximum value the simplified duration can take. As we can see the value of the error gets bigger in absolute terms as the 
time to maturity grows. This means that there is no bound in the error caused by the simplification.

\subsection{Asset Only: Coupon-Bearing Bond}

In case of a coupon-bearing bond we realize that Equation (11) and Equation (12) of Section 3.1 above hold true, hence

$$
\text { Error }=\left(\Delta P_{A}-\Delta P_{A}^{S}\right)=-\frac{1}{1+r} P_{A} \Delta r\left(D_{A}-D_{A}^{S}\right),
$$

with the same notation as before. For a bond with $T_{A}>12$ the error term becomes

$$
\text { Error }=c(r)(N-12),
$$

where $N=D_{A}$. Once and again we realize that as the duration increases, the error increases in absolute terms as well and can be practically unbounded.

In the case that the maturity of the bond is less than 12 years $\left(D_{A}<12\right)$ the error becomes

$$
\text { Error }=c(r)\left(D_{A}-D_{A}^{S}\right),
$$

where $D_{A}^{S}$ is the simplified duration that is closest to the actual one. In this case we expect a smaller error than in the previous case.

\subsection{Asset Only: Bond Portfolio}

If instead of a bond we consider a bond portfolio, then with the understanding of the formulas (6) and (7) of Section 2.4.3 we realize that the error term becomes as above

$$
\text { Error }=c(r)\left(D_{A}-D_{A}^{S}\right),
$$

where the durations (actual and simplified) this time are the ones of the portfolio. We see that the error once and again becomes higher as the duration of the asset portfolio increases, whereas the simplified duration practically remains bounded by 12 years. Consequently, for portfolios that contain assets with high maturities (and therefore durations) the error can be high enough.

\subsection{Assets and Liabilities: Immunized Portfolio}

We now consider assets and liabilities together. For simplicity we consider one asset and one liability, with one payment each, realizing that this is without loss of generality and that the discussion that follows is still applicable for a portfolio of assets and liabilities, as is indicated by the findings of Section 3.3 above. We denote by $A, L$ the present values, $T_{A}$ and $T_{L}$ the maturity dates and $D_{A}$ and $D_{L}$ the durations of the assets and the liabilities respectively. Moreover, let $r_{T_{A}}$ and $r_{T_{L}}$ be the spot rates that correspond to the maturities $T_{A}$ and $T_{L}$. Finally, we define $k$ to be the ratio of the present value of the liabilities over assets, i.e. $k=L / A$. We expect normally $k \leq 1$ for an insurance company that has enough assets to cover for its liabilities and we will therefore assume that this 
is indeed the case.

We initially consider an immunized portfolio, meaning that $D_{A}=D_{L}$ or equivalently $T_{A}=T_{L}$ as we assumed one payment both for assets and liabilities. This implies that $D_{A}^{S}=D_{L}^{S}$ or $T_{A}^{S}=T_{L}^{S}$ (using the wording of the directive that refers to maturities). If this is the case, then $r_{T_{A}}=r_{T_{L}}$. We calculate the $I R$ (up or down) with and without the simplifications using Equation (4) and Equation (5) of Section 2.4.1 to see that

$$
\begin{gathered}
I R=\left(A T_{A} r_{T_{A}}-L T_{L} r_{T_{L}}\right) \cdot \Delta r=A\left(T_{A} r_{T_{A}}-k T_{L} r_{T_{L}}\right) \cdot \Delta r \\
I R^{S}=\left(A T_{A}^{S} r_{T_{A}}-L T_{L}^{S} r_{T_{L}}\right) \cdot \Delta r=A\left(T_{A}^{S} r_{T_{A}}-k T_{L}^{S} r_{T_{L}}\right) \cdot \Delta r \\
\text { Error }=\left(I R-I R^{S}\right)=A\left(\left(T_{A}-T_{A}^{S}\right) r_{T_{A}}-k\left(T_{L}-T_{L}^{S}\right) r_{T_{L}}\right) \cdot \Delta r \\
\text { Error }=A\left(\left(T_{A}-T_{A}^{S}\right)\left(r_{T_{A}}-k r_{T_{L}}\right)\right) \cdot \Delta r=A \cdot \Delta r \cdot\left(T_{A}-T_{A}^{S}\right) r_{T_{A}}(1-k)
\end{gathered}
$$

Therefore once more

$$
\text { Error }=c(r)\left(D_{A}-D_{A}^{S}\right) .
$$

The error gets bigger as time to maturity (duration) grows. If the maturity (duration) of the asset (and liability) is greater than 12 years, then the error can be practically unbounded.

\subsection{Assets and Liabilities: Generic (Non-Immunized) Portfolio}

We start with the case where $T_{A}$ takes the maximum possible value (greater than 12) and $T_{L}$ takes the minimum possible value, lower than $1 / 2$. Therefore, their corresponding simplifications are 12 and $1 / 2$ respectively. This means that $T_{A} \gg T_{L}$ ( $\gg$ denoting very much greater) and that $T_{L}-1 / 2 \leq 1 / 2$. Furthermore we assume that the interest rate term structure is normal, hence $r_{T_{A}} \geq r_{T_{L}}$ or $-r_{T_{L}} \geq-r_{T_{A}}$. We see that

$$
\begin{gathered}
I R=\left(A T_{A} r_{T_{A}}-L T_{L} r_{T_{L}}\right) \cdot \Delta r=A\left(T_{A} r_{T_{A}}-k T_{L} r_{T_{L}}\right) \cdot \Delta r \\
I R^{S}=\left(A 12 r_{T_{A}}-L(1 / 2) r_{T_{L}}\right) \cdot \Delta r=A\left(12 r_{T_{A}}-k(1 / 2) r_{T_{L}}\right) \cdot \Delta r
\end{gathered}
$$

Therefore,

$$
\begin{aligned}
\text { Error } & =A \cdot \Delta r \cdot\left(\left(T_{A}-12\right) r_{T_{A}}-k\left(T_{L}-1 / 2\right) r_{T_{L}}\right) \\
& \geq A \cdot \Delta r \cdot\left(\left(T_{A}-12\right) r_{T_{A}}-k(1 / 2) r_{T_{L}}\right) \\
& \geq A \cdot \Delta r \cdot\left(\left(T_{A}-12\right) r_{T_{A}}-(1 / 2) r_{T_{L}}\right) \\
& \geq A \cdot \Delta r \cdot\left(\left(T_{A}-12\right)-1 / 2\right) r_{T_{A}}=A \cdot \Delta r \cdot\left(T_{A}-12.5\right) r_{T_{A}} \\
& =c\left(r_{T_{A}}\right) \cdot\left(T_{A}-12.5\right)=c\left(r_{T_{A}}\right) \cdot\left(D_{A}-12.5\right)
\end{aligned}
$$

The second inequality holds true because $T_{L}-1 / 2 \leq 1 / 2$, the third because $k \leq 1$ and the fourth because $-r_{T_{L}} \geq-r_{T_{A}}$. Consequently, the error can be unbounded, similarly to what we saw earlier for the asset only.

In the general case, where $T_{A} \gg T_{L}$, i.e. the maturity of assets is unbounded 
and the maturity of the liabilities is, and the interest rate term structure is normal, we see that

$$
\begin{gathered}
I R=\left(A T_{A} r_{T_{A}}-L T_{L} r_{T_{L}}\right) \cdot \Delta r=A\left(T_{A} r_{T_{A}}-k T_{L} r_{T_{L}}\right) \cdot \Delta r \\
I R^{S}=\left(A T_{A}^{S} r_{T_{A}}-L T_{L}^{S} r_{T_{L}}\right) \cdot \Delta r=A\left(T_{A}^{S} r_{T_{A}}-k T_{L}^{S} r_{T_{L}}\right) \cdot \Delta r \\
\text { Error }=A \cdot \Delta r \cdot\left(\left(T_{A}-T_{A}^{S}\right) r_{T_{A}}-k\left(T_{L}-T_{L}^{S}\right) r_{T_{L}}\right) \\
\geq A \cdot \Delta r \cdot\left(\left(T_{A}-T_{A}^{S}\right) r_{T_{A}}-\left(T_{L}-T_{L}^{S}\right) r_{T_{L}}\right) \\
\geq A \cdot r_{T_{A}} \cdot \Delta r \cdot\left(\left(T_{A}-T_{A}^{S}\right)-\left(T_{L}-T_{L}^{S}\right)\right) \\
=A \cdot r_{T_{A}} \cdot \Delta r \cdot\left(T_{A}-T_{A}^{S}-T_{L}+T_{L}^{S}\right) \\
\geq A \cdot r_{T_{A}} \cdot \Delta r \cdot\left(T_{A}-12-T_{L}+(1 / 2)\right) \\
=A \cdot r_{T_{A}} \cdot \Delta r \cdot\left(T_{A}-T_{L}-11.5\right) \\
=c(r)\left(T_{A}-b\right) \\
=c(r)\left(D_{A}-b\right)
\end{gathered}
$$

where $b=T_{L}+11.5$. The second inequality holds true because $k \leq 1$ and the third because $-r_{T_{L}} \geq-r_{T_{A}}$. We have assumed that $T_{L}-T_{L}^{S} \geq 0$. If it is not, then we can totally drop this term, as with the minus sign it becomes positive, and still come with a similar output. We readily see that the error term is also unbounded as the duration of the assets increases.

Finally, let us assume that $T_{L} \gg 12$ and not bounded and that $T_{A}$ is bounded-even that the maximum maturity of available assets is used. This practically reflects the unavailability of assets to match liabilities. Therefore, we see that $T_{L} \gg T_{A}$. We get as before that

$$
\begin{gathered}
I R=\left(A T_{A} r_{T_{A}}-L T_{L} r_{T_{L}}\right) \cdot \Delta r=A\left(T_{A} r_{T_{A}}-k T_{L} r_{T_{L}}\right) \cdot \Delta r \\
I R^{S}=\left(A T_{A}^{S} r_{T_{A}}-L T_{L}^{S} r_{T_{L}}\right) \cdot \Delta r=A\left(12 r_{T_{A}}-k 12 r_{T_{L}}\right) \cdot \Delta r \\
\text { Error }=A \cdot\left(\left(T_{A}-12\right) r_{T_{A}}-k\left(T_{L}-12\right) r_{T_{L}}\right) \cdot \Delta r \\
=A \cdot(-1) \cdot\left(\left(T_{L}-12\right) r_{T_{L}} k-\left(T_{A}-12\right) r_{T_{A}}\right) \cdot \Delta r \\
\mid \text { Error } \mid \geq A \cdot r_{T_{A}} \cdot \Delta r \cdot\left(\left(T_{L}-12\right) k-\left(T_{A}-12\right)\right) \\
=A \cdot r_{T_{A}} \cdot \Delta r \cdot k \cdot\left(\left(T_{L}-12 / k\right)-\left(T_{A}-12\right) / k\right) \\
\mid \text { Error } \mid \geq c(r)\left(T_{L}-b\right) \\
\mid \text { Error } \mid \geq c(r)\left(D_{L}-b\right)
\end{gathered}
$$

where $b$ is constant. This can be unbounded as the time to maturity (or duration) of the liability grows. Combining the above, we see that

$$
\mid \text { Error }|\geq c(r)| \max \left(D_{A}, D_{L}\right)-b \mid,
$$

where $b$ is constant. The error gets bigger as the time to maturity (duration) grows. For maturities (durations) that are greater than 12 years we see that the error can be unbounded. 


\section{Numerical Applications}

We perform a series of numerical applications using the guidelines of the Solvency II directive to indicate that the difference of the capital requirement as calculated with and without the simplifications can be significant. In all the examples we use the Long Term Guarantee Assessment spot curve for the interest rates, as shown in Table 4 and Figure 1 of the Appendix. The mortality table is the CSO 2001 [21].

\subsection{Single Premium Lump Sum at Maturity Endowment}

We consider an insurance policy that pays at maturity a lump sum to the policyholder if he is alive or to the beneficiaries in case the policyholder dies before maturity. The payment of the lump sum amount takes place at maturity only. We also assume that this is a single premium policy, i.e. the policyholder makes a single premium payment at the initiation of the policy and makes no other payments afterwards. We also assume that there are no expenses. In our numerical example the policyholder (male age 50) is guaranteed by the insurer an amount of 1000 Euro at the end of 20 years and that the technical interest rate (i.e. the rate of the guarantee) is $3 \%$. This means that the single premium amount is 553.68 Euro. As an asset the insurer chooses to buy a 25 -year zero-coupon corporate bond (rated A) with a face value of 500 Euro. We calculate the Best Estimate Liability (BEL) without and with the simplifications and we do the same for the asset. We realize that the drop of the interest rates results in an SCR level of 45.96 Euro without and an SCR level of 16.73 Euro with the simplification (Tables 5-7 of the Appendix). The simplification results in an underestimate of the capital requirement.

\subsection{Single Premium Lump Sum Endowment}

We now examine how the previous outcome changes if the policyholder receives the lump sum at maturity if he survives, but the policyholders receive the same amount at (the end of) the year of his death if he dies earlier. All other things remain the same. In this case we find that the drop of the interest rates results in an SCR level of 40.64 Euro without and an SCR level of 14.75 Euro with the simplification (Tables 8-10 of the Appendix). The simplification again results in an underestimate of the capital requirement.

\subsection{Regular Premium Lump Sum Endowment}

As a third example we consider a regular premium endowment. The amount is paid as a lump sum at maturity if the policyholder survives and the policyholders receive the same amount at (the end of) the year of his death if he dies earlier. In this example though the premium us paid periodically (annually). The annual premium is 23.05 Euro. In addition, we assume that the bond is coupon-bearing and pays an annual coupon of $4 \%$. We perform the same calculations to see that the drop of interest rates results in an SCR level of -9.69 Euro without the sim- 
plification and 29.25 Euro with the simplification (Tables 11-13 of the Appendix). This shows that this time there is a significant overestimation with the use of the simplification.

\section{Result Assessment}

In Sections 3 and 4 above, either with the use of mathematics or via numerical application we were able to elaborate that the use of simplifications can lead to significant discrepancies between the estimated capital requirement for the interest rate risk and the actual one. This means that the insurers may be either over or under capitalized. In the first case they draw money from the shareholders that may not be necessary. In a period during which capital is scarce, this can be a showstopper if the shareholders are not willing to provide this capital or require a high (risk-adjusted) return in order to inject such capital. The policyholders, the lenders and the regulatory authorities are the benefited parties, as the cushion of the insurer to absorb risks will be higher than needed. In the second case, the insurer will ask for less funding from the shareholders; however in such a case the insured and the lenders will be potentially facing a higher risk in case the insurer is exposed at risks that its capital is not sufficient for covering. The regulatory authorities will have to deal with a distressed company would that happen.

Policy makers may need to reconsider simplifications and rather focus on optimizing the standard formula calculations, so as to capture the idiosyncrasies of the insurance undertakings, at least with regards to the interest rate risk. We would therefore recommend, based on our findings, to move in this direction, i.e. improving the standard formula to better reflect the interest rate risk and most likely drop simplifications. This has the additional benefit of better mapping the relevant risk, which is to the interest of the insurer, the regulator, the shareholder and of course the insured.

\section{Future Research}

Our current study focused on the assessment of the simplifications that can be used for the measurement of interest rate risk. We leave for future research other forms of market risk simplifications, as well as other risk simplifications.

\section{Conclusions}

Simplifications are very important because in many cases the insurance and reinsurance undertakings could prefer to use them instead of the standard formula for the calibration of the solvency capital requirement. The simplification should be used under the condition that the technical provisions are proportionate to nature, scale and complexity of the underlying risks. It is understood though that a simplified method is required to have the accuracy of the standard formula or an internal model.

In the previous assessment the theoretical evaluation as well as the numerical 
applications indicated that there can be a significant error as a result of the assumptions underlying the simplified method for the quantification of the interest rate risk. Thus attention has to be paid so that simplifications do not lead to inadequate or over-reserved capital.

\section{Acknowledgements}

We are grateful to Marianna Anyfanti, FHAS, for the fruitful discussions we had on the topic and for letting us use her excel files and tables to confirm the calculations in our numerical applications.

\section{Conflicts of Interest}

The authors declare no conflicts of interest regarding the publication of this paper.

\section{References}

[1] European Commission (EC) (2009) Directive 2009/138/EC of the European Parliament and the Council on the Taking-Up and Pursuit of the Business of Insurance and Reinsurance (Solvency II). Official Journal of the European Union, L335.

http://eur-lex.europa.eu

[2] European Commission (EC) (2014) Commission Delegated Regulation (EU) 2015/35 of 10 October 2014 Supplementing Directive 2009/138/EC of the European Parliament and of the Council on the Taking-Up and Pursuit of the Business of Insurance and Reinsurance (Solvency II). Official Journal of the European Union, L12. http://eur-lex.europa.eu

[3] Oliver, M. (2009) Solvency II: The Story to Date, Gibraltar Financial Services Commission.

http://www.fsc.gi/uploads/legacy/download/insurance/solvencyII/Gibraltar\%20Solv ency\%20II\%20-\%20The\%20Story\%20To\%20Date\%20251109.pdf

[4] European Commission (EC) (2015) Solvency II Overview: Frequently Asked Questions, European Commission-Fact Sheet.

europa.eu/rapid/press-release_MEMO-15-3120_en.pdf

[5] Liebowitz, M.L. (1983) How Financial Theory Evolves into the Real World Or Not: The Case of Duration and Immunization. Financial Review, 18, 271-280. https://doi.org/10.1111/j.1540-6288.1983.tb00154.x

[6] Luenberger, D.G. (1998) Investment Science. Oxford University Press, Inc., New York.

[7] Redington, F.M. (1952) Review of the Principles of Life-Office Valuations. Journal of the Institute of Actuaries, 78, 286-340.

[8] Sandrom, A. (2011) Handbook of Solvency for Actuaries and Risk Managers, Theory and Practice. Chapman \& Hall/CRC, Taylor and Francis Group, USA.

[9] JPMorgan/Reuters (1996) RiskMetrics-Technical Document. 4th Edition. https://www.msci.com/documents/10199/5915b101-4206-4ba0-aee2-3449d5c7e95a

[10] Marrison, C. (2002) The Fundamentals of Risk Measurement. McGraw-Hill, USA.

[11] Van Beers, R.H.A. and Elshof, W. (2012) Evaluating the Solvency Capital Requirement of Interest Rate Risk in Solvency II. Milliman Research Report, Milliman.

[12] European Insurance and Occupational Pensions Authority (EIOPA) (2016) Discussion Paper on the Review of Specific Items in the Solvency II Delegated Regulation, 
EIOPA-CP-16/008.

[13] Gatzert, N. and Martin, M. (2012) Quantifying Credit and Market Risk under Solvency II: Standard Approach versus Internal Model. Insurance: Mathematics and Economics, 51, 649-666. https://doi.org/10.1016/j.insmatheco.2012.09.002

[14] Dirk, H. (2012) Will Solvency II Market Risk Requirements Bite? The Impact of Solvency II on Insurers' Asset Allocation. The Geneva Papers on Risk and Insurance-Issues and Practice, 38, 250-273.

[15] Braun, A., Schmeiser, H. and Schreiber, F. (2015) Portfolio Optimization under Solvency II: Implicit Constraints Imposed by the Market Risk Standard Formula. The Journal of Risk and Insurance, 84, 177-207. https://doi.org/10.1111/jori.12077

[16] Peleckiene, V. and Peleckis, K. (2014) Omnibus II Effective Measures in Adjusting the Current Solvency II Framework. Procedia-Social and Behavioral Sciences, 110, 156-163. https://doi.org/10.1016/j.sbspro.2013.12.858

[17] European Commission (EC) (2010) QIS5 Technical Specifications. https://eiopa.europa.eu

[18] European Insurance and Occupational Pensions Authority (EIOPA) (2012) Revised Technical Specifications for the Solvency II Valuation and Solvency Capital Requirements Calculations (Part I), EIOPA-DOC-12/467. https://eiopa.europa.eu

[19] European Insurance and Occupational Pensions Authority (EIOPA) (2014) Technical Specification for the Preparatory Phase (Part I). EIOPA-14/209.

https://eiopa.europa.eu

[20] European Insurance and Occupational Pensions Authority (EIOPA) (2014) The Underlying Assumptions in the Standard Formula for the Solvency Capital Requirement Calculation, EIOPA-14-322.

[21] American Academy of Actuaries (2002) Final Report of the American Academy of Actuaries' Commissioners Standard Ordinary Task Force.

http://www.actuary.org/content/cso-task-force-report 


\section{Appendix}

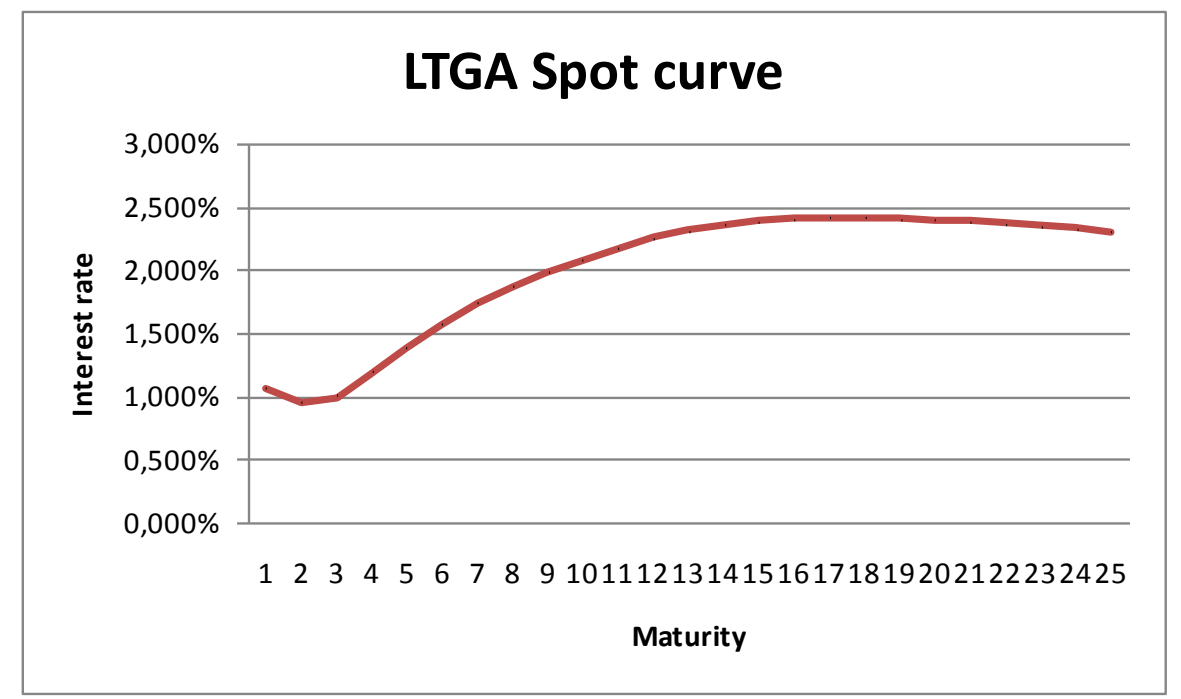

Figure 1. LTGA spot curve.

Table 4. LTGA spot curve.

\begin{tabular}{|c|c|c|c|c|c|c|c|c|c|c|c|c|c|c|c|c|c|c|c|c|c|c|c|c|c|}
\hline $\begin{array}{c}\mathrm{T} \\
\text { (maturity) }\end{array}$ & 1 & 2 & 3 & 4 & 5 & 6 & 7 & 8 & 9 & 10 & 11 & 12 & 13 & 14 & 15 & 16 & 17 & 18 & 19 & 20 & 21 & 22 & 23 & 24 & 25 \\
\hline 占 & $\begin{array}{l}\text { ம } \\
\text { ஸू } \\
\text { ঠे }\end{array}$ & $\begin{array}{l}\text { 유 } \\
\text { స్ } \\
\text { స̊ }\end{array}$ & $\begin{array}{l}\text { ம } \\
\text { ஃ̊ } \\
\text { ১. }\end{array}$ & $\begin{array}{l}{ }_{\vec{\sigma}} \\
\stackrel{\infty}{\circ} \\
\stackrel{0}{\circ}\end{array}$ & $\begin{array}{l}\text { 岕 } \\
\text { N } \\
\text { సீ }\end{array}$ & 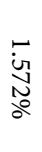 & 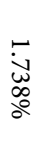 & $\begin{array}{l}\text { ம } \\
\infty \\
\infty \\
\infty \\
\infty\end{array}$ & 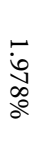 & 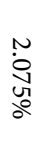 & $\begin{array}{l}\stackrel{N}{*} \\
\stackrel{\sigma}{\partial} \\
\stackrel{2}{\circ}\end{array}$ & $\begin{array}{l}\stackrel{N}{N} \\
\stackrel{\mathbb{B}}{b} \\
\stackrel{0}{0}\end{array}$ & $\begin{array}{l}\stackrel{N}{w} \\
\stackrel{0}{0} \\
\stackrel{0}{0}\end{array}$ & 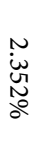 & $\begin{array}{l}\stackrel{N}{w} \\
\stackrel{\infty}{0} \\
\stackrel{0}{0}\end{array}$ & $\begin{array}{l}\stackrel{N}{w} \\
\underset{b}{0} \\
\stackrel{0}{0}\end{array}$ & 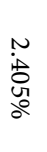 & 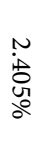 & $\begin{array}{l}N \\
\stackrel{0}{0} \\
8 \\
0\end{array}$ & 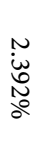 & $\begin{array}{l}\stackrel{N}{w} \\
\infty \\
O \\
0\end{array}$ & $\begin{array}{l}\stackrel{N}{w} \\
\stackrel{a}{a} \\
\stackrel{a}{a}\end{array}$ & $\begin{array}{c}\stackrel{N}{\omega} \\
\stackrel{\omega}{\omega} \\
\stackrel{0}{\circ}\end{array}$ & $\begin{array}{c}\underset{w}{w} \\
\underset{\omega}{\omega} \\
\stackrel{0}{0}\end{array}$ & $\begin{array}{l}\stackrel{N}{N} \\
\stackrel{0}{0} \\
\stackrel{\circ}{\circ}\end{array}$ \\
\hline
\end{tabular}

Table 5. Single premium lump sum at maturity endowment-Assets.

\begin{tabular}{|c|c|c|c|c|c|c|c|c|c|}
\hline & & Asset-liab & 213.80 & & & & & 167.84 & 239.52 \\
\hline \multirow[b]{2}{*}{$\mathbf{t}$} & & & 283.35 & & & & & 328.17 & 237.97 \\
\hline & $\begin{array}{l}\text { Expected } \\
\text { InFlows }\end{array}$ & $\begin{array}{l}\text { LTGA Spot } \\
\text { curve }\end{array}$ & Market Value & Down & $U_{p}$ & $\begin{array}{l}\text { LTGA } \\
\text { DOWN }\end{array}$ & $\begin{array}{l}\text { LTGA } \\
\text { UP }\end{array}$ & $\begin{array}{l}\text { Market Value } \\
\text { DOWN }\end{array}$ & $\begin{array}{c}\text { Market Value } \\
\text { UP }\end{array}$ \\
\hline 1 & - & $1.065 \%$ & - & $75 \%$ & $70 \%$ & $0.266 \%$ & $1.810 \%$ & - & - \\
\hline 2 & - & $0.962 \%$ & - & $65 \%$ & $70 \%$ & $0.337 \%$ & $1.635 \%$ & - & - \\
\hline 3 & - & $1.006 \%$ & - & $56 \%$ & $64 \%$ & $0.443 \%$ & $1.650 \%$ & - & - \\
\hline 4 & - & $1.189 \%$ & - & $50 \%$ & $59 \%$ & $0.595 \%$ & $1.891 \%$ & - & - \\
\hline 5 & - & $1.382 \%$ & - & $46 \%$ & $55 \%$ & $0.746 \%$ & $2.143 \%$ & - & - \\
\hline 6 & - & $1.572 \%$ & - & $42 \%$ & $52 \%$ & $0.912 \%$ & $2.390 \%$ & - & - \\
\hline 7 & - & $1.738 \%$ & - & $39 \%$ & $49 \%$ & $1.060 \%$ & $2.590 \%$ & - & - \\
\hline 8 & - & $1.868 \%$ & - & $36 \%$ & $47 \%$ & $1.196 \%$ & $2.746 \%$ & - & - \\
\hline 9 & - & $1.978 \%$ & - & $33 \%$ & $44 \%$ & $1.325 \%$ & $2.848 \%$ & - & - \\
\hline 10 & - & $2.075 \%$ & - & $31 \%$ & $42 \%$ & $1.432 \%$ & $2.946 \%$ & - & - \\
\hline 11 & - & $2.166 \%$ & - & $30 \%$ & $39 \%$ & $1.516 \%$ & $3.011 \%$ & - & - \\
\hline 12 & - & $2.249 \%$ & - & $29 \%$ & $37 \%$ & $1.596 \%$ & $3.080 \%$ & - & - \\
\hline
\end{tabular}




\section{Continued}

\begin{tabular}{|c|c|c|c|c|c|c|c|c|c|}
\hline 13 & - & $2.308 \%$ & - & $28 \%$ & $35 \%$ & $1.662 \%$ & $3.116 \%$ & - & - \\
\hline 14 & - & $2.352 \%$ & - & $28 \%$ & $34 \%$ & $1.694 \%$ & $3.152 \%$ & - & - \\
\hline 15 & - & $2.381 \%$ & - & $27 \%$ & $33 \%$ & $1.738 \%$ & $3.167 \%$ & - & - \\
\hline 16 & - & $2.399 \%$ & - & $28 \%$ & $31 \%$ & $1.727 \%$ & $3.142 \%$ & - & - \\
\hline 17 & - & $2.405 \%$ & - & $28 \%$ & $30 \%$ & $1.732 \%$ & $3.127 \%$ & - & - \\
\hline 18 & - & $2.405 \%$ & - & $28 \%$ & $29 \%$ & $1.731 \%$ & $3.102 \%$ & - & - \\
\hline 19 & - & $2.400 \%$ & - & $29 \%$ & $27 \%$ & $1.704 \%$ & $3.048 \%$ & - & - \\
\hline 20 & - & $2.392 \%$ & - & $29 \%$ & $26 \%$ & $1.699 \%$ & $3.014 \%$ & - & - \\
\hline 21 & - & $2.380 \%$ & - & $29 \%$ & $26 \%$ & $1.699 \%$ & $3.014 \%$ & - & - \\
\hline 22 & - & $2.364 \%$ & - & $29 \%$ & $26 \%$ & $1.699 \%$ & $3.014 \%$ & - & - \\
\hline 23 & - & $2.345 \%$ & - & $29 \%$ & $26 \%$ & $1.699 \%$ & $3.014 \%$ & - & - \\
\hline 24 & - & $2.323 \%$ & - & $29 \%$ & $26 \%$ & $1.699 \%$ & $3.014 \%$ & - & - \\
\hline 25 & 500.00 & $2.298 \%$ & 283.35 & $29 \%$ & $26 \%$ & $1.699 \%$ & $3.014 \%$ & 328.17 & 237.97 \\
\hline
\end{tabular}

Table 6. Single premium lump sum at maturity endowment-Liabilities.

\begin{tabular}{|c|c|c|c|c|c|c|c|c|c|c|c|c|c|c|c|}
\hline $\mathrm{t}$ & Age & $q x+t$ & $\mathrm{px}$ & tpx & $\begin{array}{l}\text { Expected } \\
\text { OutFlows }\end{array}$ & $\begin{array}{l}\text { Expected } \\
\text { InFlows }\end{array}$ & $\begin{array}{c}\text { Mathematical } \\
\text { Reserve }\end{array}$ & $\begin{array}{c}\text { LTGA } \\
\text { Spot curve }\end{array}$ & $\begin{array}{c}\text { Best } \\
\text { Estimate }\end{array}$ & Down & Up & $\begin{array}{l}\text { LTGA } \\
\text { DOWN }\end{array}$ & $\begin{array}{l}\text { LTGA } \\
\text { UP }\end{array}$ & $\begin{array}{c}\text { BEL } \\
\text { DOWN }\end{array}$ & BEL UP \\
\hline 0 & 50 & & 1.00000 & 1.00000 & - & 553.68 & -553.68 & & -553.68 & & & $0.000 \%$ & $0.000 \%$ & -553.68 & -553.68 \\
\hline 1 & 51 & & 1.00000 & 1.00000 & - & & - & $1.065 \%$ & - & $75 \%$ & $70 \%$ & $0.266 \%$ & $1.810 \%$ & - & - \\
\hline 2 & 52 & & 1.00000 & 1.00000 & - & & - & $0.962 \%$ & - & $65 \%$ & $70 \%$ & $0.337 \%$ & $1.635 \%$ & - & - \\
\hline 3 & 53 & & 1.00000 & 1.00000 & - & & - & $1.006 \%$ & - & $56 \%$ & $64 \%$ & $0.443 \%$ & $1.650 \%$ & - & - \\
\hline 4 & 54 & & 1.00000 & 1.00000 & - & & - & $1.189 \%$ & - & $50 \%$ & $59 \%$ & $0.595 \%$ & $1.891 \%$ & - & - \\
\hline 5 & 55 & & 1.00000 & 1.00000 & - & & - & $1.382 \%$ & - & $46 \%$ & $55 \%$ & $0.746 \%$ & $2.143 \%$ & - & - \\
\hline 6 & 56 & & 1.00000 & 1.00000 & - & & - & $1.572 \%$ & - & $42 \%$ & $52 \%$ & $0.912 \%$ & $2.390 \%$ & - & - \\
\hline 7 & 57 & & 1.00000 & 1.00000 & - & & - & $1.738 \%$ & - & $39 \%$ & $49 \%$ & $1.060 \%$ & $2.590 \%$ & - & - \\
\hline 8 & 58 & & 1.00000 & 1.00000 & - & & - & $1.868 \%$ & - & $36 \%$ & $47 \%$ & $1.196 \%$ & $2.746 \%$ & - & - \\
\hline 9 & 59 & & 1.00000 & 1.00000 & - & & - & $1.978 \%$ & - & $33 \%$ & $44 \%$ & $1.325 \%$ & $2.848 \%$ & - & - \\
\hline 10 & 60 & & 1.00000 & 1.00000 & - & & - & $2.075 \%$ & - & $31 \%$ & $42 \%$ & $1.432 \%$ & $2.946 \%$ & - & - \\
\hline 11 & 61 & & 1.00000 & 1.00000 & - & & - & $2.166 \%$ & - & $30 \%$ & $39 \%$ & $1.516 \%$ & $3.011 \%$ & - & - \\
\hline 12 & 62 & & 1.00000 & 1.00000 & - & & - & $2.249 \%$ & - & $29 \%$ & $37 \%$ & $1.596 \%$ & $3.080 \%$ & - & - \\
\hline 13 & 63 & & 1.00000 & 1.00000 & - & & - & $2.308 \%$ & - & $28 \%$ & $35 \%$ & $1.662 \%$ & $3.116 \%$ & - & - \\
\hline 14 & 64 & & 1.00000 & 1.00000 & - & & - & $2.352 \%$ & - & $28 \%$ & $34 \%$ & $1.694 \%$ & $3.152 \%$ & - & - \\
\hline 15 & 65 & & 1.00000 & 1.00000 & - & & - & $2.381 \%$ & - & $27 \%$ & $33 \%$ & $1.738 \%$ & $3.167 \%$ & - & - \\
\hline 16 & 66 & & 1.00000 & 1.00000 & - & & - & $2.399 \%$ & - & $28 \%$ & $31 \%$ & $1.727 \%$ & $3.142 \%$ & - & - \\
\hline 17 & 67 & & 1.00000 & 1.00000 & - & & - & $2.405 \%$ & - & $28 \%$ & $30 \%$ & $1.732 \%$ & $3.127 \%$ & - & - \\
\hline 18 & 68 & & 1.00000 & 1.00000 & - & & - & $2.405 \%$ & - & $28 \%$ & $29 \%$ & $1.731 \%$ & $3.102 \%$ & - & - \\
\hline 19 & 69 & & 1.00000 & 1.00000 & - & & - & $2.400 \%$ & - & $29 \%$ & $27 \%$ & $1.704 \%$ & $3.048 \%$ & - & - \\
\hline 20 & 70 & & 1.00000 & 1.00000 & 1000.00 & - & 553.68 & $2.392 \%$ & 623.23 & $29 \%$ & $26 \%$ & $1.699 \%$ & $3.014 \%$ & 714.00 & 552.13 \\
\hline
\end{tabular}


Table 7. Single premium lump sum at maturity endowment-SCR.

\begin{tabular}{ccc}
\hline \multirow{2}{*}{ Asset } & Simpl down & 22.17 \\
& Simpl up & 28.29 \\
Liability & Simpl down & 5.44 \\
& Simpl up & 6.94 \\
Company & Simpl down & 16.73 \\
& Simpl up & 21.34 \\
Company & Down & 45.96 \\
& Up & -25.72 \\
\hline
\end{tabular}

Table 8. Single premium lump sum endowment-Asset.

\begin{tabular}{|c|c|c|c|c|c|c|c|c|c|}
\hline & & Asset-liab & 188.51 & & & & & 147.87 & 212.87 \\
\hline \multirow{3}{*}{$\mathbf{t}$} & \multirow{3}{*}{$\begin{array}{l}\text { Expected } \\
\text { InFlows }\end{array}$} & \multirow{3}{*}{$\begin{array}{l}\text { LTGA Spot } \\
\text { curve }\end{array}$} & \multicolumn{2}{|l|}{283.35} & \multirow{3}{*}{$\mathrm{Up}$} & \multirow{3}{*}{$\begin{array}{c}\text { LTGA } \\
\text { DOWN }\end{array}$} & \multirow{3}{*}{$\begin{array}{l}\text { LTGA } \\
\text { UP }\end{array}$} & 328.17 & 237.97 \\
\hline & & & & & & & & Market Value & arket Value \\
\hline & & & Market Value & Down & & & & DOWN & UP \\
\hline 1 & - & $1.065 \%$ & - & $75 \%$ & $70 \%$ & $0.266 \%$ & $1.810 \%$ & - & - \\
\hline 2 & - & $0.962 \%$ & - & $65 \%$ & $70 \%$ & $0.337 \%$ & $1.635 \%$ & - & - \\
\hline 3 & - & $1.006 \%$ & - & $56 \%$ & $64 \%$ & $0.443 \%$ & $1.650 \%$ & - & - \\
\hline 4 & - & $1.189 \%$ & - & $50 \%$ & $59 \%$ & $0.595 \%$ & $1.891 \%$ & - & - \\
\hline 5 & - & $1.382 \%$ & - & $46 \%$ & $55 \%$ & $0.746 \%$ & $2.143 \%$ & - & - \\
\hline 6 & - & $1.572 \%$ & - & $42 \%$ & $52 \%$ & $0.912 \%$ & $2.390 \%$ & - & - \\
\hline 7 & - & $1.738 \%$ & - & $39 \%$ & $49 \%$ & $1.060 \%$ & $2.590 \%$ & - & - \\
\hline 8 & - & $1.868 \%$ & - & $36 \%$ & $47 \%$ & $1.196 \%$ & $2.746 \%$ & - & - \\
\hline 9 & - & $1.978 \%$ & - & $33 \%$ & $44 \%$ & $1.325 \%$ & $2.848 \%$ & - & - \\
\hline 10 & - & $2.075 \%$ & - & $31 \%$ & $42 \%$ & $1.432 \%$ & $2.946 \%$ & - & - \\
\hline 11 & - & $2.166 \%$ & - & $30 \%$ & $39 \%$ & $1.516 \%$ & $3.011 \%$ & - & - \\
\hline 12 & - & $2.249 \%$ & - & $29 \%$ & $37 \%$ & $1.596 \%$ & $3.080 \%$ & - & - \\
\hline 13 & - & $2.308 \%$ & - & $28 \%$ & $35 \%$ & $1.662 \%$ & $3.116 \%$ & - & - \\
\hline 14 & - & $2.352 \%$ & - & $28 \%$ & $34 \%$ & $1.694 \%$ & $3.152 \%$ & - & - \\
\hline 15 & - & $2.381 \%$ & - & $27 \%$ & $33 \%$ & $1.738 \%$ & $3.167 \%$ & - & - \\
\hline 16 & - & $2.399 \%$ & - & $28 \%$ & $31 \%$ & $1.727 \%$ & $3.142 \%$ & - & - \\
\hline 17 & - & $2.405 \%$ & - & $28 \%$ & $30 \%$ & $1.732 \%$ & $3.127 \%$ & - & - \\
\hline 18 & - & $2.405 \%$ & - & $28 \%$ & $29 \%$ & $1.731 \%$ & $3.102 \%$ & - & - \\
\hline 19 & - & $2.400 \%$ & - & $29 \%$ & $27 \%$ & $1.704 \%$ & $3.048 \%$ & - & - \\
\hline 20 & - & $2.392 \%$ & - & $29 \%$ & $26 \%$ & $1.699 \%$ & $3.014 \%$ & - & - \\
\hline 21 & - & $2.380 \%$ & - & $29 \%$ & $26 \%$ & $1.699 \%$ & $3.014 \%$ & - & - \\
\hline 22 & - & $2.364 \%$ & - & $29 \%$ & $26 \%$ & $1.699 \%$ & $3.014 \%$ & - & - \\
\hline 23 & - & $2.345 \%$ & - & $29 \%$ & $26 \%$ & $1.699 \%$ & $3.014 \%$ & - & - \\
\hline 24 & - & $2.323 \%$ & - & $29 \%$ & $26 \%$ & $1.699 \%$ & $3.014 \%$ & - & - \\
\hline 25 & 500.00 & $2.298 \%$ & 283.35 & $29 \%$ & $26 \%$ & $1.699 \%$ & $3.014 \%$ & 328.17 & 237.97 \\
\hline
\end{tabular}


Table 9. Single premium lump sum endowment-Liability.

\begin{tabular}{|c|c|c|c|c|c|c|c|c|c|c|c|c|c|c|}
\hline & & & & & & 26.33 & & 94.84 & & & & & 180.29 & 25.10 \\
\hline $\mathrm{t}$ & Age & $q x+t$ & tpx & $\begin{array}{l}\text { Expected } \\
\text { outflows }\end{array}$ & $\begin{array}{l}\text { Expected } \\
\text { inflows }\end{array}$ & $\begin{array}{c}\text { Mathematical } \\
\text { Reserve }\end{array}$ & $\begin{array}{c}\text { LTGA } \\
\text { Spot } \\
\text { curve }\end{array}$ & $\begin{array}{c}\text { Best } \\
\text { Estimate }\end{array}$ & Down & Up & $\begin{array}{c}\text { LTGA } \\
\text { DOWN }\end{array}$ & $\begin{array}{l}\text { LTGA } \\
\text { UP }\end{array}$ & $\begin{array}{c}\text { BEL } \\
\text { DOWN }\end{array}$ & BEL UP \\
\hline 0 & 50 & 0.003760 .99624 & 1.00000 & - & 553.68 & -553.68 & & -553.68 & & & $0.000 \%$ & $0.000 \%$ & -553.68 & -553.68 \\
\hline 1 & 51 & 0.004060 .99594 & 0.99624 & 3.76 & & 3.65 & $1.065 \%$ & 3.72 & $75 \%$ & $70 \%$ & $0.266 \%$ & $1.810 \%$ & 3.75 & 3.69 \\
\hline 2 & 52 & 0.004470 .99553 & 0.99220 & 4.04 & & 3.81 & $0.962 \%$ & 3.97 & $65 \%$ & $70 \%$ & $0.337 \%$ & $1.635 \%$ & 4.02 & 3.92 \\
\hline 3 & 53 & 0.004930 .99507 & 0.98776 & 4.44 & & 4.06 & $1.006 \%$ & 4.30 & $56 \%$ & $64 \%$ & $0.443 \%$ & $1.650 \%$ & 4.38 & 4.22 \\
\hline 4 & 54 & 0.005500 .99450 & 0.98289 & 4.87 & & 4.33 & $1.189 \%$ & 4.64 & $50 \%$ & $59 \%$ & $0.595 \%$ & $1.891 \%$ & 4.76 & 4.52 \\
\hline 5 & 55 & 0.006170 .99383 & 0.97748 & 5.41 & & 4.66 & $1.382 \%$ & 5.05 & $46 \%$ & $55 \%$ & $0.746 \%$ & $2.143 \%$ & 5.21 & 4.86 \\
\hline 6 & 56 & 0.006880 .99312 & 0.97145 & 6.03 & & 5.05 & $1.572 \%$ & 5.49 & $42 \%$ & $52 \%$ & $0.912 \%$ & $2.390 \%$ & 5.71 & 5.23 \\
\hline 7 & 57 & 0.007640 .99236 & 0.96477 & 6.68 & & 5.43 & $1.738 \%$ & 5.92 & $39 \%$ & $49 \%$ & $1.060 \%$ & $2.590 \%$ & 6.21 & 5.59 \\
\hline 8 & 58 & 0.008270 .99173 & 0.95740 & 7.37 & & 5.82 & $1.868 \%$ & 6.36 & $36 \%$ & $47 \%$ & $1.196 \%$ & $2.746 \%$ & 6.70 & 5.93 \\
\hline 9 & 59 & 0.008990 .99101 & 0.94948 & 7.92 & & 6.07 & $1.978 \%$ & 6.64 & $33 \%$ & $44 \%$ & $1.325 \%$ & $2.848 \%$ & 7.03 & 6.15 \\
\hline 10 & 60 & 0.009860 .99014 & 0.94095 & 8.54 & & 6.35 & $2.075 \%$ & 6.95 & $31 \%$ & $42 \%$ & $1.432 \%$ & $2.946 \%$ & 7.40 & 6.38 \\
\hline 11 & 61 & 0.010940 .98906 & 0.93167 & 9.28 & & 6.70 & $2.166 \%$ & 7.33 & $30 \%$ & $39 \%$ & $1.516 \%$ & $3.011 \%$ & 7.86 & 6.69 \\
\hline 12 & 62 & 0.012250 .98775 & 0.92148 & 10.19 & & 7.15 & $2.249 \%$ & 7.81 & $29 \%$ & $37 \%$ & $1.596 \%$ & $3.080 \%$ & 8.43 & 7.08 \\
\hline 13 & 63 & 0.013710 .98629 & 0.91019 & 11.29 & & 7.69 & $2.308 \%$ & 8.39 & $28 \%$ & $35 \%$ & $1.662 \%$ & $3.116 \%$ & 9.11 & 7.57 \\
\hline 14 & 64 & 0.015240 .98476 & 0.89771 & 12.48 & & 8.25 & $2.352 \%$ & 9.01 & $28 \%$ & $34 \%$ & $1.694 \%$ & $3.152 \%$ & 9.86 & 8.08 \\
\hline 15 & 65 & 0.016850 .98315 & 0.88403 & 13.68 & & 8.78 & $2.381 \%$ & 9.61 & $27 \%$ & $33 \%$ & $1.738 \%$ & $3.167 \%$ & 10.56 & 8.57 \\
\hline 16 & 66 & 0.018470 .98153 & 0.86913 & 14.90 & & 9.28 & $2.399 \%$ & 10.19 & $28 \%$ & $31 \%$ & $1.727 \%$ & $3.142 \%$ & 11.33 & 9.08 \\
\hline 18 & 68 & 0.021850 .97815 & 0.83594 & 17.14 & & 10.07 & $2.405 \%$ & 11.17 & $28 \%$ & $29 \%$ & $1.731 \%$ & $3.102 \%$ & 12.58 & 9.89 \\
\hline 19 & 69 & 0.023640 .97636 & 0.81768 & 18.27 & & 10.42 & $2.400 \%$ & 11.64 & $29 \%$ & $27 \%$ & $1.704 \%$ & $3.048 \%$ & 13.25 & 10.32 \\
\hline 20 & 70 & 0.025770 .97423 & 0.79835 & 817.68 & - & 452.73 & $2.392 \%$ & 509.60 & $29 \%$ & $26 \%$ & $1.699 \%$ & $3.014 \%$ & 583.82 & 451.46 \\
\hline
\end{tabular}

Table 10. Single premium lump sum endowment-SCR.

\begin{tabular}{ccc}
\hline \multirow{2}{*}{ Asset } & Simpl down & 22.17 \\
& Simpl up & 28.29 \\
Liability & Simpl down & 7.42 \\
& Simpl up & 9.47 \\
Company & Simpl down & 14.75 \\
& Simpl up & 18.82 \\
Company & Down & 40.64 \\
& Up & -24.36 \\
\hline
\end{tabular}

Table 11. Regular premium lump sum endowment-Assets.

\begin{tabular}{ccccccccc}
\hline & Asset-liab & 373.76 & & & 383.45 & 346.03 \\
\hline & & 664.69 & & & & 739.74 & 588.95 \\
\hline $\mathbf{t}$ & $\begin{array}{c}\text { Expected } \\
\text { InFlows }\end{array}$ & $\begin{array}{c}\text { LTGA Spot } \\
\text { curve }\end{array}$ & Market Value & Down & Up & $\begin{array}{c}\text { LTGA } \\
\text { DOWN }\end{array}$ & $\begin{array}{c}\text { LTGA } \\
\text { UP }\end{array}$ & $\begin{array}{c}\text { Market ValueMarket Value } \\
\text { DOWN }\end{array}$ \\
\hline
\end{tabular}




\section{Continued}

\begin{tabular}{|c|c|c|c|c|c|c|c|c|c|}
\hline 1 & 20.00 & $1.065 \%$ & 19.79 & $75 \%$ & $70 \%$ & $0.266 \%$ & $1.810 \%$ & 19.95 & 19.64 \\
\hline 2 & 20.00 & $0.962 \%$ & 19.62 & $65 \%$ & $70 \%$ & $0.337 \%$ & $1.635 \%$ & 19.87 & 19.36 \\
\hline 3 & 20.00 & $1.006 \%$ & 19.41 & $56 \%$ & $64 \%$ & $0.443 \%$ & $1.650 \%$ & 19.74 & 19.04 \\
\hline 4 & 20.00 & $1.189 \%$ & 19.08 & $50 \%$ & $59 \%$ & $0.595 \%$ & $1.891 \%$ & 19.53 & 18.56 \\
\hline 5 & 20.00 & $1.382 \%$ & 18.67 & $46 \%$ & $55 \%$ & $0.746 \%$ & $2.143 \%$ & 19.27 & 17.99 \\
\hline 6 & 20.00 & $1.572 \%$ & 18.21 & $42 \%$ & $52 \%$ & $0.912 \%$ & $2.390 \%$ & 18.94 & 17.36 \\
\hline 7 & 20.00 & $1.738 \%$ & 17.73 & $39 \%$ & $49 \%$ & $1.060 \%$ & $2.590 \%$ & 18.58 & 16.72 \\
\hline 8 & 20.00 & $1.868 \%$ & 17.25 & $36 \%$ & $47 \%$ & $1.196 \%$ & $2.746 \%$ & 18.19 & 16.10 \\
\hline 9 & 20.00 & $1.978 \%$ & 16.77 & $33 \%$ & $44 \%$ & $1.325 \%$ & $2.848 \%$ & 17.77 & 15.53 \\
\hline 10 & 20.00 & $2.075 \%$ & 16.29 & $31 \%$ & $42 \%$ & $1.432 \%$ & $2.946 \%$ & 17.35 & 14.96 \\
\hline 11 & 20.00 & $2.166 \%$ & 15.80 & $30 \%$ & $39 \%$ & $1.516 \%$ & $3.011 \%$ & 16.95 & 14.43 \\
\hline 12 & 20.00 & $2.249 \%$ & 15.32 & $29 \%$ & $37 \%$ & $1.596 \%$ & $3.080 \%$ & 16.54 & 13.90 \\
\hline 13 & 20.00 & $2.308 \%$ & 14.87 & $28 \%$ & $35 \%$ & $1.662 \%$ & $3.116 \%$ & 16.14 & 13.42 \\
\hline 14 & 20.00 & $2.352 \%$ & 14.44 & $28 \%$ & $34 \%$ & $1.694 \%$ & $3.152 \%$ & 15.81 & 12.95 \\
\hline 15 & 20.00 & $2.381 \%$ & 14.05 & $27 \%$ & $33 \%$ & $1.738 \%$ & $3.167 \%$ & 15.44 & 12.53 \\
\hline 16 & 20.00 & $2.399 \%$ & 13.69 & $28 \%$ & $31 \%$ & $1.727 \%$ & $3.142 \%$ & 15.21 & 12.19 \\
\hline 17 & 20.00 & $2.405 \%$ & 13.35 & $28 \%$ & $30 \%$ & $1.732 \%$ & $3.127 \%$ & 14.94 & 11.85 \\
\hline 18 & 20.00 & $2.405 \%$ & 13.04 & $28 \%$ & $29 \%$ & $1.731 \%$ & $3.102 \%$ & 14.68 & 11.54 \\
\hline 19 & 20.00 & $2.400 \%$ & 12.74 & $29 \%$ & $27 \%$ & $1.704 \%$ & $3.048 \%$ & 14.51 & 11.31 \\
\hline 20 & 20.00 & $2.392 \%$ & 12.46 & $29 \%$ & $26 \%$ & $1.699 \%$ & $3.014 \%$ & 14.28 & 11.04 \\
\hline 21 & 20.00 & $2.380 \%$ & 12.20 & $29 \%$ & $26 \%$ & $1.699 \%$ & $3.014 \%$ & 14.04 & 10.72 \\
\hline 22 & 20.00 & $2.364 \%$ & 11.96 & $29 \%$ & $26 \%$ & $1.699 \%$ & $3.014 \%$ & 13.81 & 10.41 \\
\hline 23 & 20.00 & $2.345 \%$ & 11.74 & $29 \%$ & $26 \%$ & $1.699 \%$ & $3.014 \%$ & 13.58 & 10.10 \\
\hline 24 & 20.00 & $2.323 \%$ & 11.53 & $29 \%$ & $26 \%$ & $1.699 \%$ & $3.014 \%$ & 13.35 & 9.81 \\
\hline 25 & 520.00 & $2.298 \%$ & 294.68 & $29 \%$ & $26 \%$ & $1.699 \%$ & $3.014 \%$ & 341.29 & 247.49 \\
\hline
\end{tabular}

Table 12. Regular premium lump sum endowment_Liabilities.

\begin{tabular}{|c|c|c|c|c|c|c|c|c|c|c|c|c|c|c|c|}
\hline & & & & & & & 247.63 & & 290.93 & & & & & 356.29 & 242.92 \\
\hline $\mathrm{t}$ & Age & $q x+t$ & $\mathrm{px}$ & $\operatorname{tpx}$ & $\begin{array}{l}\text { Expected } \\
\text { OutFlows }\end{array}$ & $\begin{array}{l}\text { Expected } \\
\text { InFlows }\end{array}$ & $\begin{array}{c}\text { Mathematical } \\
\text { Reserve }\end{array}$ & $\begin{array}{c}\text { LTGA } \\
\text { Spot curve }\end{array}$ & $\begin{array}{c}\text { Best } \\
\text { Estimate }\end{array}$ & Down & $\mathrm{Up}$ & $\begin{array}{c}\text { LTGA } \\
\text { DOWN }\end{array}$ & $\begin{array}{l}\text { LTGA } \\
\text { UP }\end{array}$ & $\begin{array}{c}\text { BEL } \\
\text { DOWN }\end{array}$ & BEL UP \\
\hline 0 & 50 & 0.00376 & 0.99624 & 1.00000 & - & 23.05 & -23.05 & & -23.05 & & & $0.000 \%$ & $0.000 \%$ & -23.05 & -23.05 \\
\hline 1 & 51 & 0.00406 & 0.99594 & 0.99624 & 3.76 & 22.96 & -18.64 & $1.065 \%$ & -19.00 & $75 \%$ & $70 \%$ & $0.266 \%$ & $1.810 \%$ & -19.15 & -18.86 \\
\hline 2 & 52 & 0.00447 & 0.99553 & 0.99220 & 4.04 & 22.87 & -17.74 & $0.962 \%$ & -18.47 & $65 \%$ & $70 \%$ & $0.337 \%$ & $1.635 \%$ & -18.70 & -18.22 \\
\hline 3 & 53 & 0.00493 & 0.99507 & 0.98776 & 4.44 & 22.77 & -16.78 & $1.006 \%$ & -17.79 & $56 \%$ & $64 \%$ & $0.443 \%$ & $1.650 \%$ & -18.09 & -17.45 \\
\hline 4 & 54 & 0.00550 & 0.99450 & 0.98289 & 4.87 & 22.66 & -15.80 & $1.189 \%$ & -16.96 & $50 \%$ & $59 \%$ & $0.595 \%$ & $1.891 \%$ & -17.37 & -16.50 \\
\hline 5 & 55 & 0.00617 & 0.99383 & 0.97748 & 5.41 & 22.53 & -14.77 & $1.382 \%$ & -15.99 & $46 \%$ & $55 \%$ & $0.746 \%$ & $2.143 \%$ & -16.50 & -15.40 \\
\hline 6 & 56 & 0.00688 & 0.99312 & 0.97145 & 6.03 & 22.39 & -13.70 & $1.572 \%$ & -14.90 & $42 \%$ & $52 \%$ & $0.912 \%$ & $2.390 \%$ & -15.49 & -14.20 \\
\hline
\end{tabular}




\section{Continued}

\begin{tabular}{|c|c|c|c|c|c|c|c|c|c|c|c|c|c|c|}
\hline 7 & 57 & 0.00764 & 0.992360 .96477 & 6.68 & 22.24 & -12.65 & $1.738 \%$ & -13.79 & $39 \%$ & $49 \%$ & $1.060 \%$ & $2.590 \%$ & -14.45 & -13.01 \\
\hline 8 & 58 & 0.00827 & 0.991730 .95740 & 7.37 & 22.07 & -11.60 & $1.868 \%$ & -12.67 & $36 \%$ & $47 \%$ & $1.196 \%$ & $2.746 \%$ & -13.36 & -11.83 \\
\hline 9 & 59 & 0.00899 & 0.991010 .94948 & 7.92 & 21.89 & -10.71 & $1.978 \%$ & -11.71 & $33 \%$ & $44 \%$ & $1.325 \%$ & $2.848 \%$ & -12.41 & -10.85 \\
\hline 10 & 60 & 0.00986 & 0.990140 .94095 & 8.54 & 21.69 & -9.79 & $2.075 \%$ & -10.71 & $31 \%$ & $42 \%$ & $1.432 \%$ & $2.946 \%$ & -11.41 & -9.84 \\
\hline 11 & 61 & 0.01094 & 0.989060 .93167 & 9.28 & 21.48 & -8.81 & $2.166 \%$ & -9.64 & $30 \%$ & $39 \%$ & $1.516 \%$ & $3.011 \%$ & -10.34 & -8.80 \\
\hline 12 & 62 & 0.01225 & 0.987750 .92148 & 10.19 & 21.24 & -7.75 & $2.249 \%$ & -8.46 & $29 \%$ & $37 \%$ & $1.596 \%$ & $3.080 \%$ & -9.14 & -7.68 \\
\hline 13 & 63 & 0.01371 & 0.986290 .91019 & 11.29 & 20.98 & -6.60 & $2.308 \%$ & -7.20 & $28 \%$ & $35 \%$ & $1.662 \%$ & $3.116 \%$ & -7.82 & -6.50 \\
\hline 14 & 64 & 0.01524 & 0.984760 .89771 & 12.48 & 20.69 & -5.43 & $2.352 \%$ & -5.93 & $28 \%$ & $34 \%$ & $1.694 \%$ & $3.152 \%$ & -6.49 & -5.32 \\
\hline 15 & 65 & 0.01685 & 0.983150 .88403 & 13.68 & 20.38 & -4.30 & $2.381 \%$ & -4.70 & $27 \%$ & $33 \%$ & $1.738 \%$ & $3.167 \%$ & -5.17 & -4.19 \\
\hline 16 & 66 & 0.01847 & 0.981530 .86913 & 14.90 & 20.03 & -3.20 & $2.399 \%$ & -3.52 & $28 \%$ & $31 \%$ & $1.727 \%$ & $3.142 \%$ & -3.91 & -3.13 \\
\hline 17 & 67 & 0.02009 & 0.979910 .85308 & 16.05 & 19.66 & -2.18 & $2.405 \%$ & -2.41 & $28 \%$ & $30 \%$ & $1.732 \%$ & $3.127 \%$ & -2.70 & -2.14 \\
\hline 18 & 68 & 0.02185 & 0.978150 .83594 & 17.14 & 19.27 & -1.25 & $2.405 \%$ & -1.39 & $28 \%$ & $29 \%$ & $1.731 \%$ & $3.102 \%$ & -1.56 & -1.23 \\
\hline 19 & 69 & 0.02364 & 0.976360 .81768 & 18.27 & 18.85 & -0.33 & $2.400 \%$ & -0.37 & $29 \%$ & $27 \%$ & $1.704 \%$ & $3.048 \%$ & -0.42 & -0.33 \\
\hline 20 & 70 & 0.02577 & 0.974230 .79835 & 817.68 & - & 452.73 & $2.392 \%$ & 509.60 & $29 \%$ & $26 \%$ & $1.699 \%$ & $3.014 \%$ & 583.82 & 451.46 \\
\hline
\end{tabular}

Table 13. Regular premium lump sum endowment-SCR.

\begin{tabular}{ccc}
\hline \multirow{2}{*}{ Asset } & Simpl down & 52.01 \\
& Simpl up & 66.36 \\
Liability & Simpl down & 22.76 \\
& Simpl up & 29.04 \\
Company & Simpl down & 29.25 \\
& Simpl up & 37.31 \\
Company & Down & -9.69 \\
\hline
\end{tabular}

